\title{
Thin-Film Strain Gauge Sensors for Ion Thrust Measurement
}

\author{
R. John Stephen, K. Rajanna, Vivek Dhar, K. G. Kalyan Kumar, and S. Nagabushanam
}

\begin{abstract}
In order to measure the thrust produced by a stationary plasma thruster, a measurement system has been developed using a thrust balance with thin-film strain gauge sensors. For this purpose, strain gauges were designed and deposited on the columns of the thrust balance fabricated and necessary signal conditioning circuits have been used. The performance of the system developed was studied, in a vacuum chamber under space simulated conditions, by activating the thruster. In situ calibration was done using Lami's principle. For discharge powers varying from 210-275 W, the measured values of thrust were found to be in the range of 11-16 mN with an accuracy of $\pm 1 \mathrm{mN}$ and resolution of $0.12 \mathrm{mN}$. Specific impulse and efficiency were also estimated.
\end{abstract}

Index Terms-Stationary plasma thruster, thin-film strain gauge, thrust balance.

\section{INTRODUCTION}

$\mathbf{I}$ N SPACE applications, a kind of propulsion is used to reorient satellites placed in orbits. In recent years, Hall-type electric propulsion devices, such as stationary plasma thrusters (SPTs), placed on board the satellites are activated for the purpose of station keeping and on-orbit maneuvering [1]-[7]. In such situations, measurement of thrust is an important requirement. Techniques have been developed for the measurement of thrust produced by electric propulsion devices based on spring force, pendulum, and a gas-bearing turntable [8]-[14]. Recently, we have reported the measurement of thrust produced by an SPT, using a thrust balance with conventional foil type of strain gauges [15]. In comparison with conventional foil-type strain gauges, thin-film strain gauges offer several advantages. Some of the advantages are the absence of adhesive material, flexibility to tailor the properties of the sensor material in thin-film form, good linearity, and improved strain sensitivity, etc. [16], [17]

In this paper, we report the attempt made to measure the thrust produced by an SPT by developing a measurement system using a thrust balance with thin-film strain gauges made of platinum-tungsten (Pt-W) material. This material has been chosen because of its high sensitivity, good repeatability, and excellent linearity. The details of the experiments carried out to study

Manuscript received October 24, 2002; revised May 5, 2003. This work was supported by the Department of Space, Indian Space Research Organization (ISRO) Satellite Centre, Bangalore, India. The associate editor coordinating the review of this paper and approving it for publication was Dr. Pavel Ripka.

R. J. Stephen and K. Rajanna are with the Department of Instrumentation, Indian Institute of Science (IISc), Bangalore-560 012, India (e-mail: rjstephen@rediffmail.com; kraj@isu.iisc.ernet.in).

V. Dhar, K. G. K. Kumar, and S. Nagabushanam are with the Control Systems Group, Indian Space Research organization (ISRO) Satellite Centre, Bangalore-560 017, India (e-mail: vdhar@isac.ernet.in; bkc@isac.ernet.in; snaga@isac.ernet.in).

Digital Object Identifier 10.1109/JSEN.2004.827276

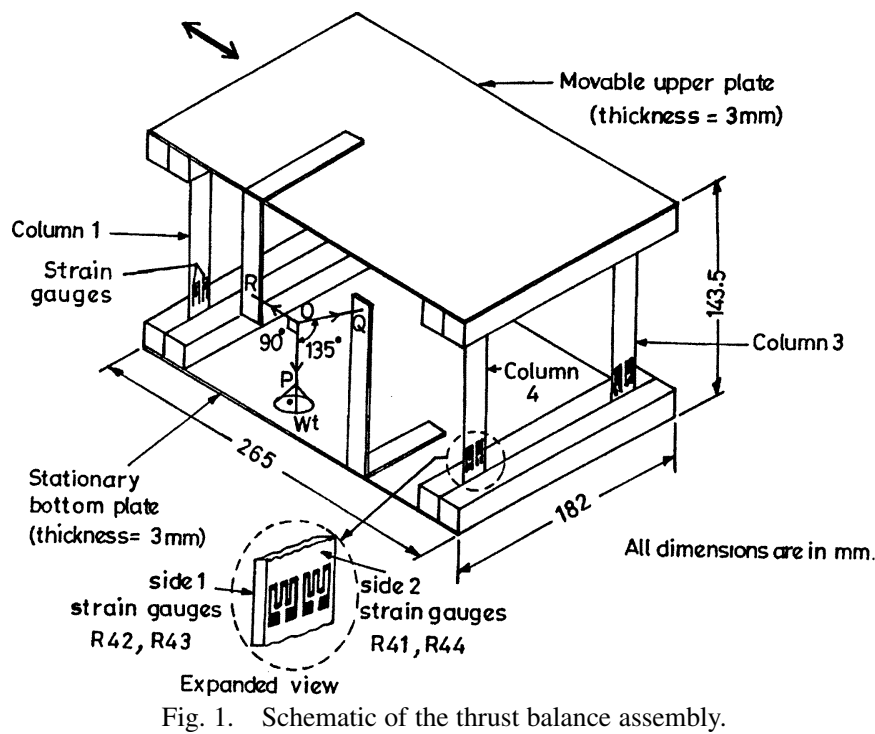

the performance of the thrust measuring system on the ground under space-simulated conditions and the results obtained are reported.

\section{EXPERIMENTAL}

\section{A. Thrust Balance Assembly}

The schematic of the thrust balance assembly developed is shown in Fig. 1. It consists of a stainless steel (SS) plate at the bottom with four columns of beryllium-copper alloy, mounted one on each of the four corners, simply supporting another SS plate at the top. Its bottom plate is stationary and its upper plate moves in response to a force while remaining parallel to the bottom plate. When the thrust balance is critically loaded, the columns buckle and even a small force in the transverse direction produces a large deflection of the columns, the deflection being proportional to the magnitude of the force acting on them. An SPT was placed on the upper plate along with additional weights, so as to critically load the thrust balance in such a way that the four columns share the total load equally. To provide damping during the operation of the thruster, a viscous damper was provided. More details of the thrust balance are provided in our earlier paper [15].

\section{B. Preparation of Thin-Film Strain Gauges}

The strain gauge development carried out includes the design of strain gauge, surface preparation of the columns, deposition of thin-film gauges, wiring, and necessary signal conditioning. Thin-film strain gauges had to be deposited on the region of the four columns of the thrust balance, where the 


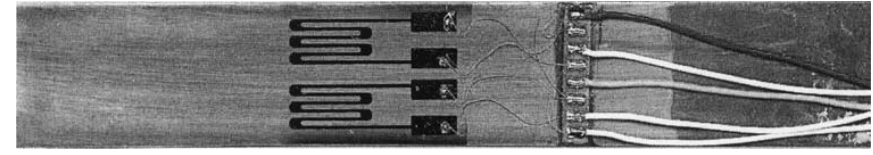

Fig. 2. Photograph showing a portion of the thrust balance column onto which thin-film strain gauges are deposited and wired.

strain is maximum. This region was found to be at a distance of approximately $30 \%$ of the length of the column from its either end. For the sake of convenience, the lower region of the columns was chosen to deposit the thin-film strain gauges. The suitable pattern required for the thin-film strain gauge was first designed using AutoCAD. A photo plot of the designed gauge pattern was obtained and, with the help of it, mechanical masks of beryllium-copper material and $150-\mu$ thickness, were also made. In order to electrically isolate the thin-film strain gauges from the metallic surface, a thin layer of polymer (M-Bond 610 of Measurements Group, Inc.) was applied on either side of the columns. This polymer is suitable for temperatures up to $+230{ }^{\circ} \mathrm{C}$. Prior to the application of the polymer layer, the surface of the columns was prepared using standard polishing and cleaning procedures. The polymer layer was applied uniformly on the required region and heat treatment of the columns was done immediately in a temperature-controlled oven at $175{ }^{\circ} \mathrm{C}$ for about $2 \mathrm{~h}$.

Using the mechanical masks, thin-film strain gauges were deposited at the desired region on either side of the four columns using the dc magnetron sputtering technique. This technique has been chosen because of its high ionization efficiency and good adhesion of the deposited films. Good adhesion of films and, hence, better molecular bonds ensure faithful transfer of strain experienced by the columns to the gauges. The sputtering system used consists of an arrangement in which a plasma discharge is maintained between the anode or substrate (beryllium-copper columns) and the cathode or target (92\% platinum and $8 \%$ tungsten).

The chamber was initially evacuated to a pressure of $10^{-6}$ torr using a combination of rotary and diffusion pump and back filled to sputtering pressure with the inert gas argon. The deposition parameters were optimized to achieve the required properties for the film. Following the deposition process, the columns were cured in an oven. Later, the gauges were connected in a Wheatstone bridge configuration such that the pair of gauges on either side of the column forms the opposite arms of the bridge. A photograph of the thin-film strain gauges deposited on one of the columns with the electrical wiring is shown in Fig. 2.

The block diagram of the measurement system is as shown in Fig. 3. The necessary signal conditioning circuitry utilized includes an instrumentation amplifier. The detailed aspects of the electronic circuitry utilized are provided in an earlier paper [15].

\section{Gauge Factor Determination}

In order to determine the gauge factor of the thin-film strain gauges deposited, a mechanical setup was designed and developed. The setup consists of a rectangular base plate made of stainless steel material with a cylindrical rod fixed vertically at the left wherein a fixture has been provided for holding the strain gauge columns in the form of a cantilever. The free end of the

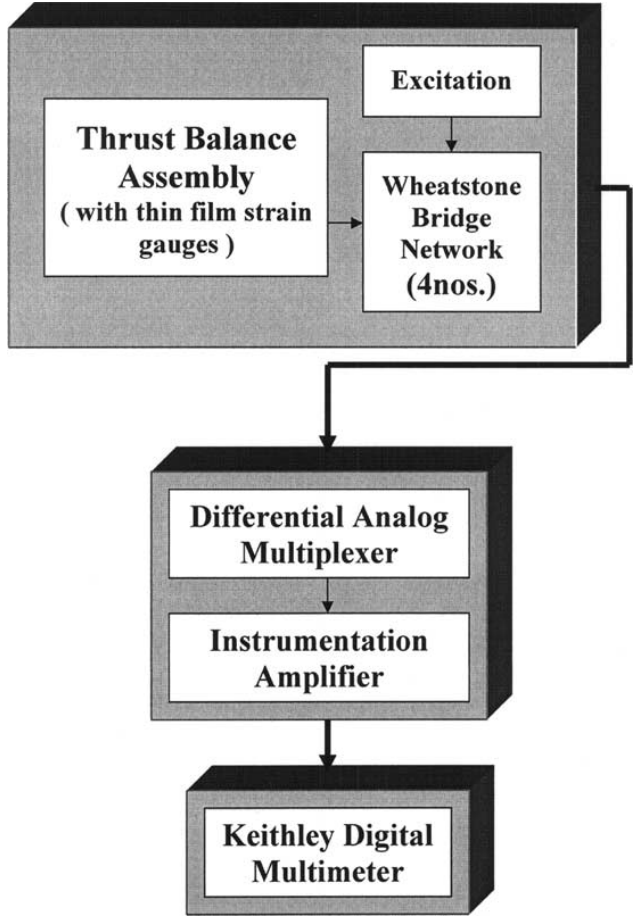

Fig. 3. Block diagram of the measurement system.

cantilever can be deflected by means of a screw gauge (micrometer) fixed to a holder on the dovetail arrangement, which can be made to move back and forth along the length of the base plate.

The free end of the cantilever was deflected in steps and the corresponding bridge output voltages were recorded. The variation of the deflection versus bridge output voltage for different excitation voltages was studied and found to be linear. This is shown in Fig. 4(a). Also, small masses were added in steps to the free end of the cantilever and the corresponding bridge output voltages were noted. Variation of the mass versus output voltage is as shown in Fig. 4(b). From the data obtained, the gauge factor of the thin-film strain gauges was determined. The measured gauge factor was found to be $\sim 3.5$ for the Pt-W thin-film strain gauges.

\section{System Calibration and Performance Study}

In order to have a calibration of the output voltage from the thrust measurement system, an arrangement was made in the thrust balance using a fine silk thread with a pan, as shown in Fig. 1. The thread was tied such that the plane PQR was parallel to the vertical plane of the thrust balance. An MS nut of mass $1.03 \mathrm{gm}$ was attached to point $\mathrm{P}$ of the thread, whereas points $\mathrm{Q}$ and $\mathrm{R}$ were tied to the thrust balance. The thread $\mathrm{OR}$ was parallel to the horizontal plane and the thread OP was hanging vertically downward due to the weight attached to its lower end. Thus $\angle \mathrm{POR}=90^{\circ}$. Point $\mathrm{Q}$ of the thread was tied to the thrust balance such that $\angle \mathrm{POQ}=\angle \mathrm{ROQ}=135^{\circ}$. If $\mathbf{F}_{\mathbf{P}}$ is the force acting along $\mathrm{OP}, \mathbf{F}_{\mathbf{Q}}$ the force acting along $\mathrm{OQ}$, and $\mathbf{F}_{\mathbf{R}}$ the force acting along OR, then, as per Lami's theorem

$$
\begin{aligned}
\frac{\mathbf{F}_{\mathbf{P}}}{\operatorname{Sin} \angle \mathrm{ROQ}} & =\frac{\mathbf{F}_{\mathbf{R}}}{\operatorname{Sin} \angle \mathrm{POQ}}=\frac{\mathbf{F}_{\mathbf{Q}}}{\operatorname{Sin} \angle \mathrm{POR}} \\
\frac{\mathbf{F}_{\mathbf{P}}}{\operatorname{Sin} 135^{\circ}} & =\frac{\mathbf{F}_{\mathbf{R}}}{\operatorname{Sin} 135^{\circ}}=\frac{\mathbf{F}_{\mathbf{Q}}}{\operatorname{Sin} 90^{\circ}} \\
\therefore \mathbf{F}_{\mathbf{P}} & =\mathbf{F}_{\mathbf{R}} .
\end{aligned}
$$




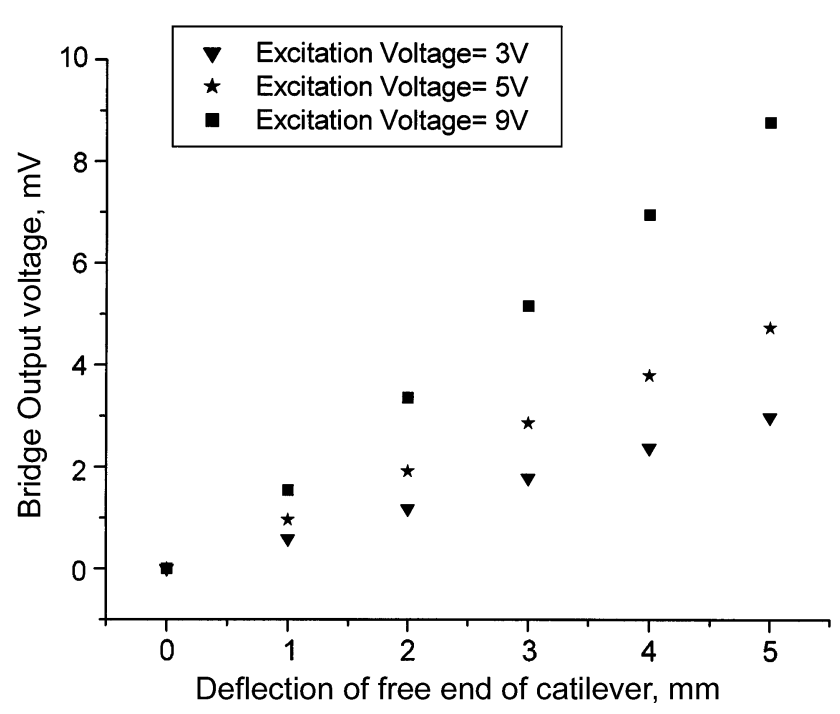

(a)

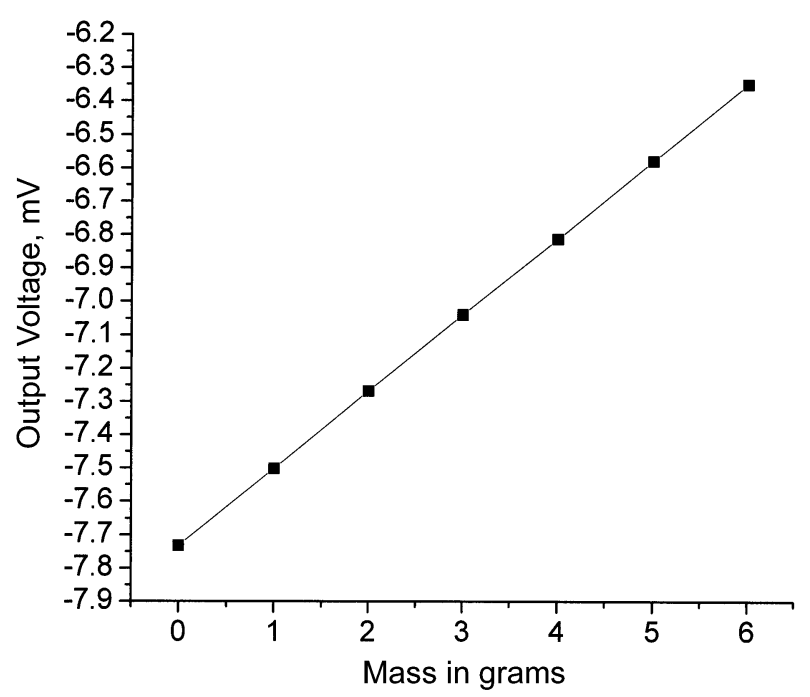

(b)

Fig. 4. (a) Beam deflection versus output voltage for different excitation voltages. (b) Variation of the mass versus output voltage.

The downward force $\mathbf{F}_{\mathbf{P}}$ due to a mass of $1.03 \mathrm{gm}$ acting along OP is equal to the product of mass and the acceleration due to gravity, which is $10.1 \mathrm{mN}$. Hence, the force $\mathbf{F}_{\mathbf{R}}$ acting along OR is also equal to $10.1 \mathrm{mN}$.

The vacuum chamber used for the purpose of measurement is a cylindrical chamber of 1.2-m diameter and 1.4-m length made of stainless steel material. A combination of rotary, turbo molecular, and cryo pumps was used to obtain pressures as low as $10^{-6}$ torr. The rotary and the turbo molecular pumps have been mounted on rubber pads to minimize vibration and have been connected to the vacuum chamber through metallic bellows so as to reduce the transmission of vibrations to the chamber.

While performing the actual in situ calibration, the thrust balance was placed on a horizontal platform inside the cylindrical vacuum chamber. The SPT was placed atop the thrust balance and the thrust balance was critically loaded. Care was taken to see that the connections to the thruster were made in such a way that cable torque forces were negligible. An MS mass of $1.03 \mathrm{gm}$ was attached to point $\mathrm{P}$ of the thread arrangement shown in Fig. 1. A solenoid was used around the mass attached

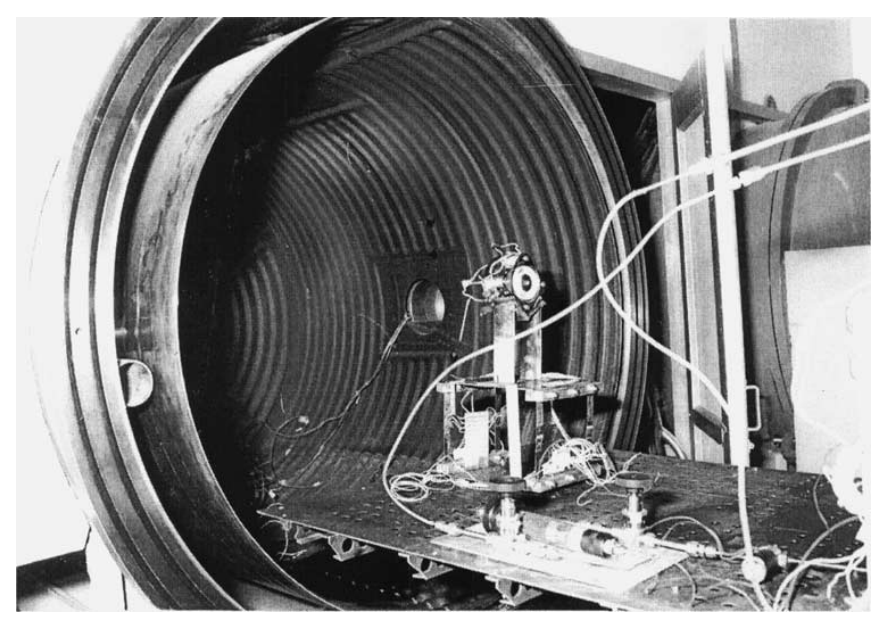

Fig. 5. Photograph of the thrust balance along with the thruster placed inside the vacuum chamber.

to point $\mathrm{P}$, in order to lift it whenever required. In order to protect the strain gauges from direct ion impingement on them during the operation of the thruster, a stainless steel enclosure was placed surrounding the columns of the thrust balance. The chamber was evacuated to a pressure of $10^{-6}$ torr and in situ calibration was done with the propellant flow $\mathrm{ON}$ at a pressure of $10^{-4}$ mbar. When the solenoid is in the normal state, the mass hangs vertically downwards due to the force of gravity. At this condition, the output voltage from the measurement system was noted. The solenoid was then energized and when the mass was thus lifted, the output voltage was once again noted. The difference between these two voltages correspond to a force of $1.03 \times 9.8=10.1 \mathrm{mN}$. This was repeated a few times to check the consistency of the change in the output voltage corresponding to the force of $10.1 \mathrm{mN}$ and the values were found to be almost consistent with a variation of less than $5 \%$. This change in output voltage was utilized as follows, in estimating the thrust produced when the thruster was activated. The SPT was operated and the actual change in the output voltage before and after the firing of the thruster was noted. Thus, the output thrust produced by the SPT is given by

$$
\text { Thrust }=\frac{(\text { Change in output voltage })}{(\text { Voltage change during in situ calibration) }}
$$

Fig. 5 shows the photograph of the thrust balance along with the thruster placed inside the vacuum chamber. In order to operate the thruster, the flow rate of xenon gas was set to $0.821 \mathrm{mg} / \mathrm{s}$. The thruster was operated as per standard procedure for electric propulsion thrusters. By varying the anode voltage and current, the thrust produced by the propellant for various discharge powers was measured from each of the four columns. The experiment was also repeated for xenon flow rates of 0.889 and $0.957 \mathrm{mg} / \mathrm{s}$. An in situ calibration check was also performed immediately after switching off the thruster. It has been found that the calibration remained unaltered. Care was taken to eliminate the possible noise in the output signal by providing proper shielding and grounding in the following manner. The cables, connecting the strain gauges deposited on the columns of the thrust balance placed in the vacuum chamber to the signal conditioner module and the power supplies kept 


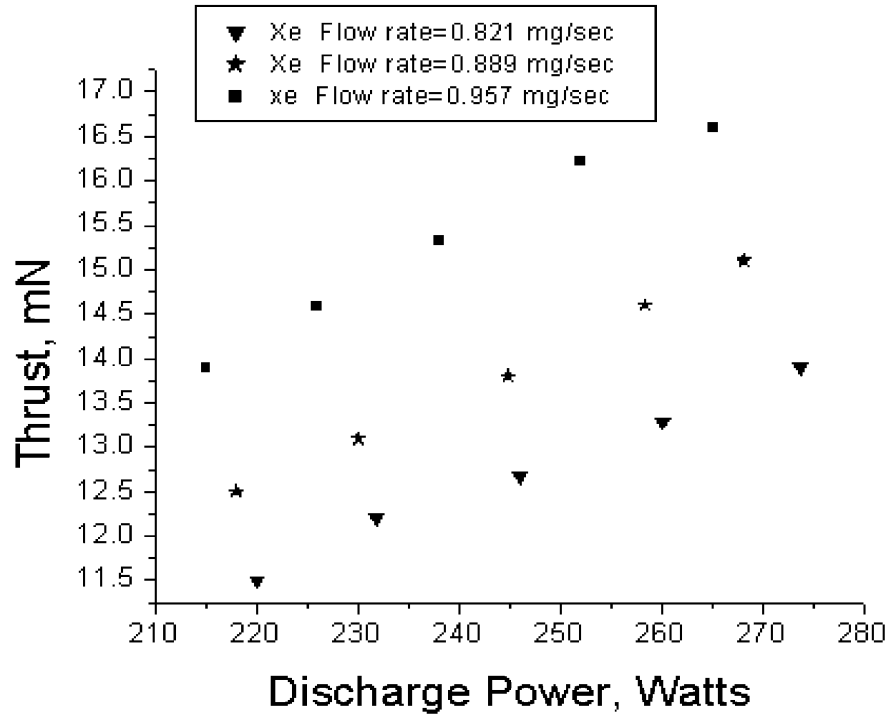

Fig. 6. Variation of the thrust with discharge power.

outside the chamber, were shielded using flexible copper conducting tape. Apart from this, proper grounding of the thrust balance, the SS enclosure, and the shroud of the vacuum chamber were also done for the above purpose. In addition to these, graphite blocks were placed inside the chamber at the closed end of the shroud, $\sim 1 \mathrm{~m}$ downstream of the thruster exit plane so as to form a background ion dump, which was held at ground potential. The experiment was repeated several times and it was found that the values of thrust estimated from the measured data from each column were almost same and the variation was less than a milliNewton. The variation of the thrust produced versus thruster discharge power is shown in Fig. 6. It can be seen that the thrust produced increases almost linearly with the discharge power. The measured values of thrusts were found to be approximately in the range of $11-16 \mathrm{mN}$ for discharge powers of 210-275 W. Also, the specific impulse and the thrust efficiency were determined from the measured values of thrust using the following relations [15]:

$$
\begin{aligned}
\mathrm{I}_{\mathrm{sp}} & =\frac{\mathrm{T}}{\mathrm{mg}} \\
\eta_{\mathrm{T}} & =\frac{0.5 \mathrm{~m}\left[\mathrm{I}_{\mathrm{sp}} \cdot \mathrm{g}\right]^{2}}{\mathrm{~V}_{\mathrm{d}} \mathrm{I}_{\mathrm{d}}}
\end{aligned}
$$

where $T$ is the thrust, $I_{s p}$ is the specific impulse, $m$ is the mass flow rate of xenon, $\eta_{\mathrm{T}}$ is the thruster efficiency, $\mathrm{V}_{\mathrm{d}}$ is the discharge voltage, and $I_{d}$ is the discharge current. The product $V_{d} I_{d}$ is the discharge power. For the mentioned range of discharge power, the specific impulse was found to vary from 1430 to $1800 \mathrm{~s}$ and the thrust efficiency was found to vary from $36 \%$ to $57 \%$. The variation of the specific impulse, and the thruster efficiency with the thruster discharge power are shown in Figs. 7 and 8, respectively. In general, the thrust, specific impulse and efficiency were found to decrease as the mass flow rate was reduced. This behavior may be attributed to the reduction in ionization probability at low mass flow rates resulting in a reduced propellant utilization [18].

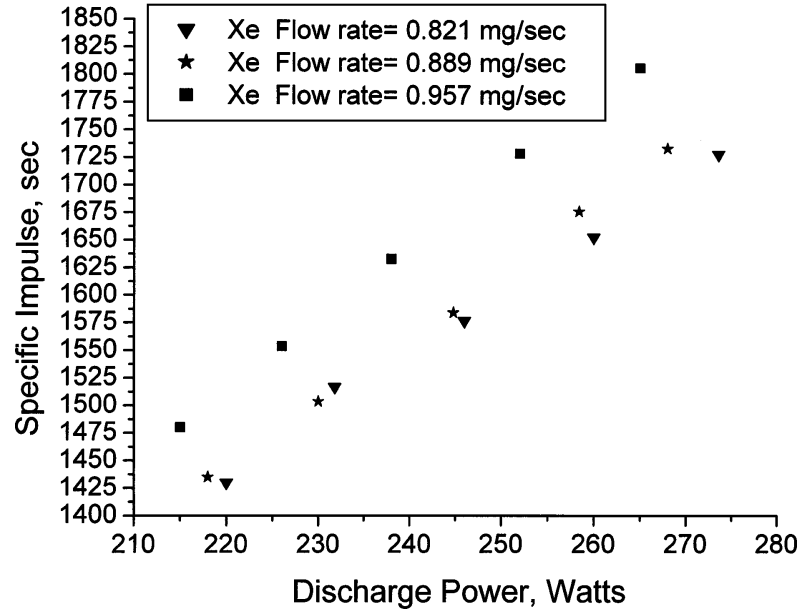

Fig. 7. Variation of the specific impulse with discharge power.

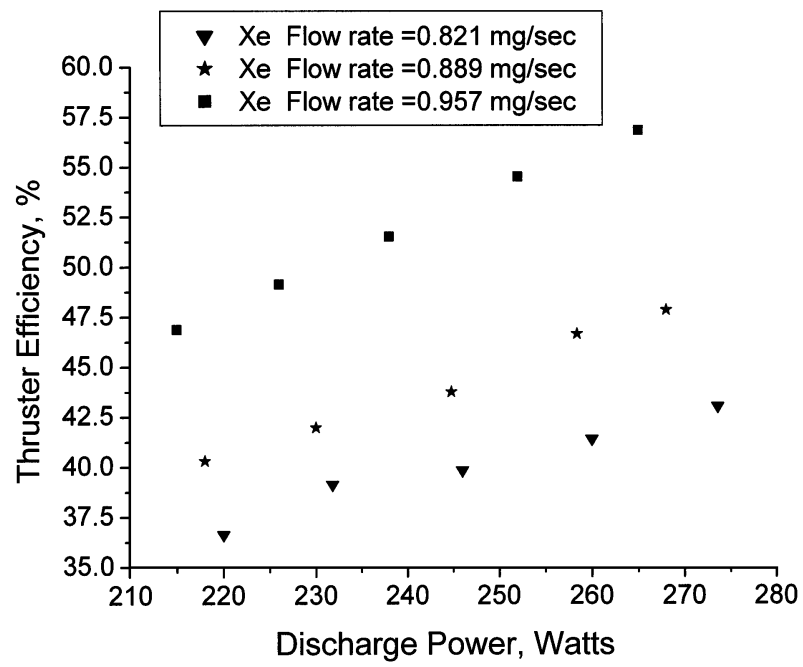

Fig. 8. Variation of thruster efficiency with discharge power.

\section{CONCLUSION}

A thrust measurement system for measuring the thrust produced by a stationary plasma thruster has been developed using a thrust balance with thin-film strain gauge sensors and associated signal conditioning circuitry. The output performance of the thrust measurement system has been studied in a vacuum chamber under space-simulated conditions by activating the thruster for various discharge powers using xenon as the propellant. In comparision with the thrust measurement system using conventional foil type strain gauges [15], the presently reported system with thin-film strain gauges is found to have higher sensitivity, better stability and linearity, and very good repeatability. However, thermal drift was found to exist in the present system, which can be overcome by using suitable temperature compensation techniques. Specific impulses and the thrust efficiency have also been determined.

\section{ACKNOWLEDGMENT}

The authors would like to thank the Chairman, Department of Instrumentation, IISc and Group Director, Control Systems Group, ISAC for their encouragement in carrying out this work. They would also like to thank all the colleagues of the respective groups in both the organizations for their help, as well as 
Dr. M. M. Nayak, Manager, Advanced Transducers Division, LPSC, Bangalore, for his many useful discussions and suggestions during the course of this work.

\section{REFERENCES}

[1] G. Saccoccia, D. Estublier, and G. D. Racca, "SMART-1 a technology demonstration mission for science using electric propulsion," in Proc. 34th AIAA/ASME/SAE/ASEE Joint Propulsion Conf. Exhibit, Cleveland, OH, July 13-15, 1998.

[2] K. Makowski, Z. Peradzynski, N. Gascon, and M. Dudeck, "A stationary model for stationary plasma thruster (SPT) discharge," in Proc. 34th AIAA/ASME/SAE/ASEE Joint Propulsion Conf. Exhibit, Los Angeles, CA, June 20-24, 1999.

[3] L. Garrigues, A. Heron, J. C. Adam, and J. P. Boeuf, "Comparisons between hybrid \& PIC models of stationary plasma thruster," in Proc. 34th AIAA/ASME/SAE/ASEE Joint Propulsion Conf. Exhibit, Los Angeles, CA, June 20-24, 1999.

[4] S. Roche, S. Barral, S. Bechu, M. Dudeck, P. Lasgorceix, L. Magne, T. Minea, D. Pagnon, and M. Touzeau, "Thermal analysis of a stationary plasma thruster," in Proc. 34th AIAA/ASME/SAE/ASEE Joint Propulsion Conf. Exhibit, Los Angeles, CA, June 20-24, 1999.

[5] J. P. Boeul and L. Garrigues, "Low frequency oscillations in a stationary plasma thruster," J. Appl. Phys., vol. 84, no. 7, p. 3541, 1998.

[6] M. Day, N. Maslennikov, T. Randolph, and W. Rogers, "SPT-100 subsystem qualification status," in Proc. 34th AIAA/ASME/SAE/ASEE Joint Propulsion Conf. Exhibit, San Diego, CA, July 10-12, 1995.

[7] D. T. Jacobson and R. S. Jankovsky, "Test results of a $200 \mathrm{~W}$ class hall thruster," in Proc. 34th AIAA/ASME/SAE/ASEE Joint Propulsion Conf. Exhibit, Cleveland, OH, July 13-15, 1998.

[8] T. W. Haag, "Thrust stand for high-power electric propulsion devices," Rev. Sci. Instrum., vol. 62, no. 5, p. 1186, 1991.

[9] H. Murakami, M. Hirata, and I. Kudo, "Thrust measurement of an ion engine system," J. Spacecraft, vol. 21, no. 1, p. 96, 1984.

[10] W. E. Morren, M. V. Whalen, and J. S. Sovey, "Performance and endurance tests of laboratory model multipropellant resistojet," J. Propulsion, vol. 6, no. 1, p. 18, 1990 .

[11] A. Sasoh and Y. Arakawa, "A high-resolution thrust stand for ground tests of low-thrust space propulsion devices," Rev. Sci. Instrum., vol. 64, no. 3, p. 719, 1993.

[12] J. E. Pollard and R. P. Welle, "Thrust vector measurements with T5 ion engine," in Proc. 31 st AIAA Joint Propulsion Conf., San Deigo, CA, July $10-12,1995$.

[13] H. Tahara, Y. Nikai, T. Yasui, and T. Yoshikawa, "Hall thruster research at Osaka University," in Proc. 34th AIAA/ASME/SAE/ASEE Joint Propulsion Conf. Exhibit, Los Angeles, CA, June 20-24, 1999.

[14] D. Manzella, S. Oleson, J. Sankovic, T. Haag, A. Semenkin, and V. Kim, "Evaluation of low power hall thruster propulsion," in Proc. 34th AIAA/ASME/SAE/ASEE Joint Propulsion Conf. Exhibit, Lake Buena Vista, FL, July 1-3, 1996.

[15] R. J. Stephen, K. Rajanna, V. Dhar, K. G. K. Kumar, and S. Nagabhusanam, "Strain gauge based thrust measurement system for a stationary plasma thruster," Meas. Sci. Technol., vol. 12, p. 1568, 2001.

[16] P. R. Perino, "Thin film strain gauge transducers," Instrum. Contr. Syst., vol. 38, p. 119,1965

[17] K. Rajanna, S. Mohan, and E. S. R. Gopal, "Thin film strain gauges-an overview," Indian J. Pure Appl. Phys., vol. 27, p. 453, 1989.

[18] Y. Raitses, J. Ashkenazy, and M. Guelman, "Propellant utilization in hall thrusters," J. Propulsion Power, vol. 14, p. 247, 1998.

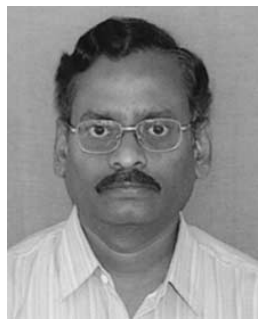

R. John Stephen was born in Tiruchirapalli, Tamilnadu, India, in 1957. He received the B.E. degree in electronics and instrumentation from Annamalai University, India, in 1982 and the M.Tech. degree in instrumentation technology from the Indian Institute of Science (IISc), Bangalore, India, in 1988. He is currently pursuing the Ph.D. degree at the Department of Instrumentation, IISc.

After a short stay in industry for a period of about two years, he joined the Siddaganga Institute of Technology (SIT), Tumkur, Kamataka, India, as a Lecturer in 1984. Since 1992, he has been an Assistant Professor with the Department of Instrumentation and Electronics, SIT. He has published in both national as well as in international journals. His fields of interest include control systems, process control, and instrumentation.

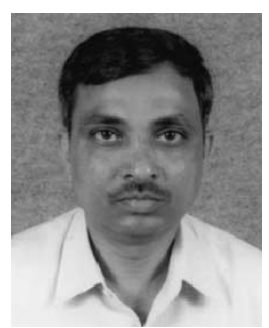

K. Rajanna was born in the Shimoga district of Kamataka, India. He received the M.Sc. degree in physics from the University of Mysore, India, in 1976 and the M.Sc. (Eng.) and Ph.D. degrees from the Indian Institute of Science (IISc), Bangalore, in 1988 and 1993, respectively.

Currently, he is an Associate Professor with the Department of Instrumentation, IISc. He was a Visiting Fellow of the Japan Society for the Promotion of Science (JSPS) twice from 1997 to 1998 at the Toyohashi University of Technology, Japan. He was also a Visiting Professor at the Tohoku University, Japan, from 2000 and 2002. He has published in national as well as leading international journals. His current areas of interest include thin-film sensors and microsensors (including microelectromechanical systems), vacuum and thin-film technology, and novel material engineering for sensor applications.

Dr. Rajanna was a member of the Editorial Review Committee of the IEEE TRANSACTIONS ON INSTRUMENTATION AND MEASUREMENT.

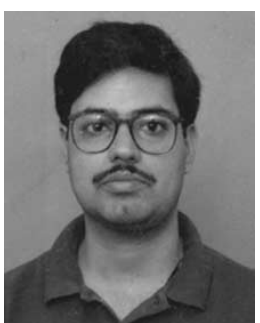

Vivek Dhar received the B.E. degree in mechanical engineering from the Regional Engineering College, Allahabad, India, in 1992. He is currently pursuing the M.Tech. degree in machine design at the Indian Institute of Technology, Madras.

$\mathrm{He}$ has been an Engineer with the Indian Space Research Organization (ISRO) Satellite Centre, Bangalore, for the past eight years. He is a coauthor of internationally published papers on the use of strain gauges for thrust measurement. His interests include buckling of columns, development of mechanical packages for electronic subsystems, and stationary plasma thrusters.

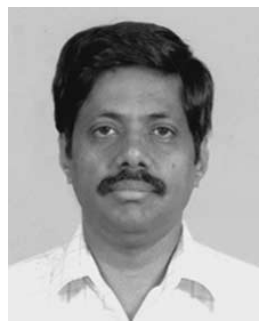

K. G. Kalyan Kumar received the Bachelor of Science degree in science and the Post Graduate Diploma in instrumentation from Bangalore University, Bangalore, India, in 1975 and the Master of Science degree in physics from Annamalai University, India, in 1985.

He joined the Indian Space Research Organization (ISRO), Bangalore, in 1978. As a Deputy Manager at the Environmental Test Facility, ISRO, he looked after the operation and maintenance of environmental test chambers apart from building new facilities for special needs. Presently, he is with the Control Systems Group, ISRO, for the realization of spacecraft electric propulsion systems and the creation of associated test setups.

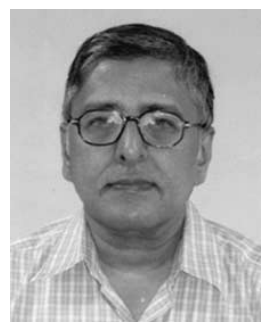

S. Nagabushanam received the Master of Science degree in machine design from the Indian Institute of Technology, Madras, in 1972.

$\mathrm{He}$ has been with the Indian Space Research organization (ISRO) Satellite Centre, Bangalore, since 1973. As Head of the Control Components Division, he looks after all the mechanical aspects regarding spacecraft control systems hardware, testing, and simulation. His areas of interest include dry lubrication, magnetic suspension, magnetic torquer, and conventional and electric propulsion. 